НАУКИ О ЗЕМЛЕ

"НАУКА. ИННОВАЦИИ. ТЕХНОЛОГИИ", №4, 2019

25.00 .12

УДК 550.814:528.71

Харченко В.М., Лапта Д.В.,

Неркарарян A.E. kafgog@ncfu.ru

\section{КОМПЛЕКСНЫЕ ДИСТАНЦИОННЫЕ И ГЕОФИЗИЧЕСКИЕ МЕТОДЫ ПОИСКОВ ЗАЛЕЖЕЙ УГЛЕВОДОРОДОВ (территория Центрального Предкавказья)}

Введение:

ГЕОЛОГИЯ, ПОИСКИ И РАЗВЕДКА НЕФТЯНЫХ И ГАЗОВЫХ МЕСТОРОЖДЕНИЙ
Северо-Кавказский федеральный университет, г. Ставрополь, Россия

актуальность исследований комплекса дистанционных и геофизических методов поисков залежей углеводородов обусловлена необходимостью повышения эффективности не только поисков и разведки, но и разработки уже существующих месторождений нести и газа в России. Предоставленные исследования, помогут в выявлении новых месторождениях углеводородов, а также сравнительно сократят затраты на их разведку.

Материалы и методы

исследований: $\quad$ исходными материалами и методами данных исследований являются комплексная интерпретация Нурин-Хагской кольцевой космофотоаномалий (ККФА) на территории Калмыкии [4]. А также, материалы работы «Создание цифровой модели гравитационного и магнитного полей территории Предкавказья» [2].

Результаты исследований

и их обсуждение: в результате интерпретации данных исследований, показаны новые результаты по комплексным дистанционным и геофизическим методам поисков залежей углеводородов и выделение наиболее перспективных территорий на примере территории Центрального Предкавказья.

Выводы: $\quad$ Оперативный, основательно аргументированный и экономически целесообразный прогноз скоплений УВ в настоящее время немыслим без применения комплекса магнитных и гравитационных методов. Эти методы становятся не только неотъемлемым, но и первым звеном поисковых работ на нефть и газ в различных регионах страны и мира.

Ключевые слова: дистанционные методы поисков УВ, геофизические методы поисков УВ, геофизический критерий нефтегазоносности, магнитные поля, гравитационные поля, гравитационные аномалии, магнитные аномалии, Нурин-Хагская космофоотоаномалия, Центральное Предкавказье. 
Kharchenko V.M., North Caucasus Federal University, Stavropol, Russia

Lapta D.V.,

Nerkararyan A.E. $\quad$ kafgog@ncfu.ru

\section{Integrated Remote and Geophysical Methods \\ for Searching Deposits of Hydrocarbons \\ (Territory of the Central Caucasus Caucasus)}

Introduction: the relevance of researching a complex of remote and geophysical methods for searching for hydrocarbon deposits is due to the need to increase the efficiency of not only prospecting and exploration, but also the development of existing oil and gas fields in Russia. The research provided will help in identifying new hydrocarbon deposits, as well as relatively reduce the costs of

Materials and research their exploration.

methods:

the starting materials and methods of these studies are a comprehensive interpretation of the Nurin-Hag ring cosmophotomalancies (CCFA) in Kalmykia [4]. And also, the materials of the work «Creating a digital model of the gravitational and magnetic fields of the territory of the Ciscaucasia» [2].

Research results and discussion:

as a result of the interpretation of the research data, new results are shown on integrated remote and geophysical methods for searching for hydrocarbon deposits and identifying the most promising territories using the territory of the Central Ciscaucasia as an example.

Conclusions: An operational, thoroughly reasoned and economically feasible forecast of hydrocarbon accumulations is currently unthinkable without the use of a complex of magnetic and gravitational methods. These methods are becoming not only integral, but also the first link in the search for oil and gas in various regions of the country and the world.

Keywords: remote methods for hydrocarbon searches, geophysical methods for hydrocarbon searches, geophysical criterion of oil and gas potential, magnetic fields, gravitational fields, gravitational anomalies, magnetic anomalies, NurinKhag cosmophotomanalia, Central Ciscaucasia.

\section{Введение}

Принципиальная возможность проведения геологической разведки на основе изучения различных физических полей Земли определяется тем, что распределение параметров полей на поверхности или в глубине Земли, акватории зависит не только от общего строения Земли и, но и от происхождения или способа создания полей, т. е. от нормального поля, и от неоднородностей геологической среды, создающих аномальные поля. Иными словами, геофизика служит для выявления аномалий физических полей, обусловленных неоднородностями геологического строения, связанных с изменением физических свойств и геометрических параметров слоев, геологических или техногенных объектов. Геофизическая информация отражает физико-геологические неоднородности среды в плане, по глубине и во времени. При этом возникновение аномалий связано с тем, что объект поисков, назы- 
ваемый возмущающим, либо сам создает поля в силу естественных причин, например, повышенной намагниченности, либо искажает искусственное поле вследствие различий физических свойств.

Выявление геофизических аномалий [3] - сложная техническая и математическая проблема, поскольку оно проводится на фоне не всегда однородного и спокойного нормального поля, а среди разнообразных помех геологического, природного, техногенного характера (неоднородности верхней части геологической среды, неровности рельефа, космические, атмосферные, климатические, промышленные и другие помехи). Измерив те или иные физические параметры по системам обычно параллельных профилей или маршрутов и выявив аномалии, можно судить о свойствах пород и о геологическом строении района исследований

Получаемые аномалии определяются, прежде всего, изменением физических свойств горных пород по площади и по глубине. Например, гравитационное поле зависит от изменения плотности пород $\sigma$, магнитное поле - от магнитной восприимчивости $\chi$ и остаточной намагниченности Ir.

Гравиметрический метод разведки основан на изучении аномального гравитационного поля, обусловленного геологическим строением и разной плотностью пород земной коры и внутренних зон Земли на земной поверхности. Гравитационные аномалии есть следствие различной плотности горных пород и особенностей залегания слагаемых ими геологических структур, рудных тел и вмещающих пород. На картах выделяют максимальные и минимальные аномалии.

Магнитометрический метод разведочной геофизики основан на изучении аномалий геомагнитного поля, вызванных различиями магнитных свойств горных пород в земной коре. Формирование аномального поля связано преимущественно с магнитной неоднородностью пород кристаллического фундамента, а также с проникающими в осадочную толщу интрузиями и эффузиями преимущественно основного состава. Аномальное геомагнитное поле отображается на картах линиями равных значений вектора напряженности $\Delta \mathrm{Ta}$, горизонтальных $\Delta$ На или вертикальных $\Delta \mathrm{Za} \mathrm{его} \mathrm{составляющих.}$

Геофизический критерий нефтегазоносности СЦТ трактуется приуроченностью к ним различных геофизических полей: магнитного, гравитационного, электрического и теплового, которые располагаются в центральной части СЦТ или по концентрическим линиям различного радиуса, что связано с распределением полей тектонических напряжений и с основными потоками флюидов.

Научная новизна заключается в том, что новый подход использования дистанционных методов поисков залежей углеводородов дает возможность выявить структурные и неструктурные ловушки полезных ископаемых, а уже при их интерпретации выделяются перспективные участки, содержащие полезные ископаемые, в том числе нефть и газ. 
Актуальность исследований комплекса дистанционных и геофизических методов поисков залежей углеводородов обусловлена необходимостью повышения эффективности не только поисков и разведки, но и разработки уже существующих месторождений, обеспечивая высокую детальность, разрешенность и точность изучения геологической среды.

Целью данной работы является выявление перспективности нефтегазоносности Центрального Предкавказья, при помощи комплекса дистанционных и геофизических методов поисков залежей УВ.

\section{Материалы и методы исследований}

Геофизические критерии поисков и разведки МПИ основывается на проведении комплекса геофизических работ на участках, выделенных по кольцевым космофотоаномалиям. Нефтегазоносность таких структур трактуется приуроченностью к ним магнитного поля и отсутствием гравитационного поля, которые располагаются в центральной части структуры или по концентрическим линиям различного радиуса. Особенностью данной методики поисков и разведки МПИ является признак отсутствия гравитационных аномалий в местах сильно выраженных магнитных аномалий, что может явиться прямым признаком залежей УВ над последней. Это объясняется компенсацией отрицательной гравитационной аномалии над залежью УВ нижележашей положительной аномалией, которую обуславливают более плотные, железосодержащие горные породы или флюиды с магнитосодержащими элементами [4-5].

Примером может служит Нурин-Хагская площадь в Калмыкии (рис. 1), где к ее центральной части приурочивается отчетливо выраженная магнитная аномалия, которая обусловлена фундаментом, сложенным железистыми кварцитами архей-протерозойского возраста, или вулкано-плутоническими центрами палеозойского возраста.

В 1986-1987 гг. Калмыцкой НГРЭ совместно с Саратовским университетом были проведены площадные и профильные геохимические исследования через центр ККФА и Алексеевскую площадь. В результате этих работ были выявлены геохимические аномалии (по содержанию метана и суммы тяжелых УВ) в центральной части ККФА и в районе Алексеевской площади (скв. 5) (рис. 2).

В начальный период анализа и сопоставления выделенной Нурин-Хагской кольцевой космофотоаномалии (ККФА) с различными геофизическими данными отмечена приуроченность центральной части ККФА с аномалией магнитного поля на фоне нулевых и отрицательных значений, а также практически полное совпадение с выступом докембрийского фундамента на глу- 


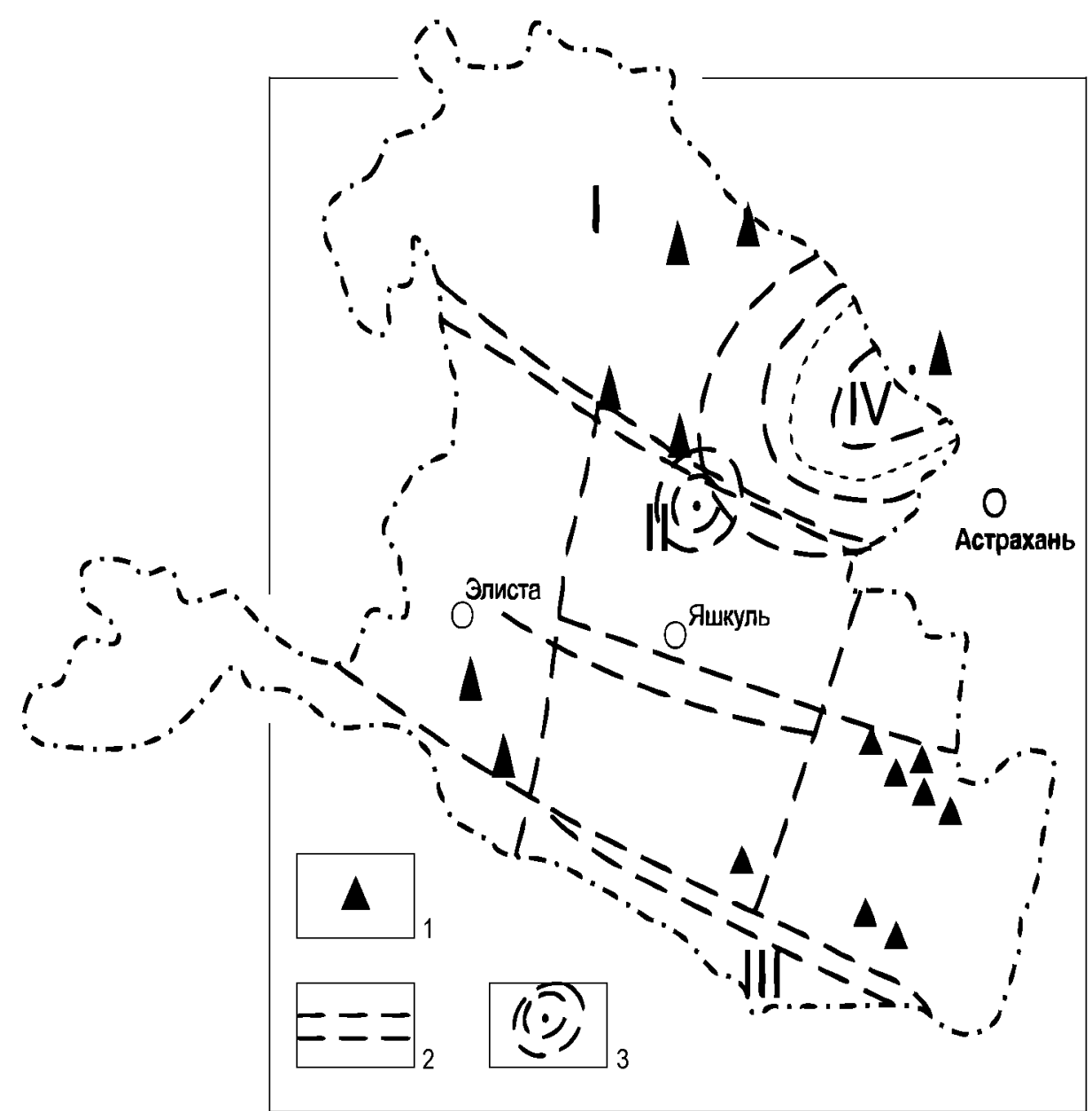

Pис. 1.

Схема расположения Нурин-Хагской космофоотономалии на территории Калмыкии:

I - Прикаспийская впадина,

II - Кряж Карпинского,

III - Кумо-Манычская впадина,

IV - Астраханский свод

1 - Месторождение нефти и газа,

2 - Зона тектонических нарушений,

3 - кольцевые структуры.

Fig. 1. The layout of the Nurin-Khag cosmophotoanomaly on the territory of Kalmykia:

I- Caspian depression,

II - Karpinsky ridge,

III - Kumo-Manych depression,

IV - Astrakhan arch.

1 - Oil and gas field,

2 -zone of tectonic disturbances,

3 -ring structures. 


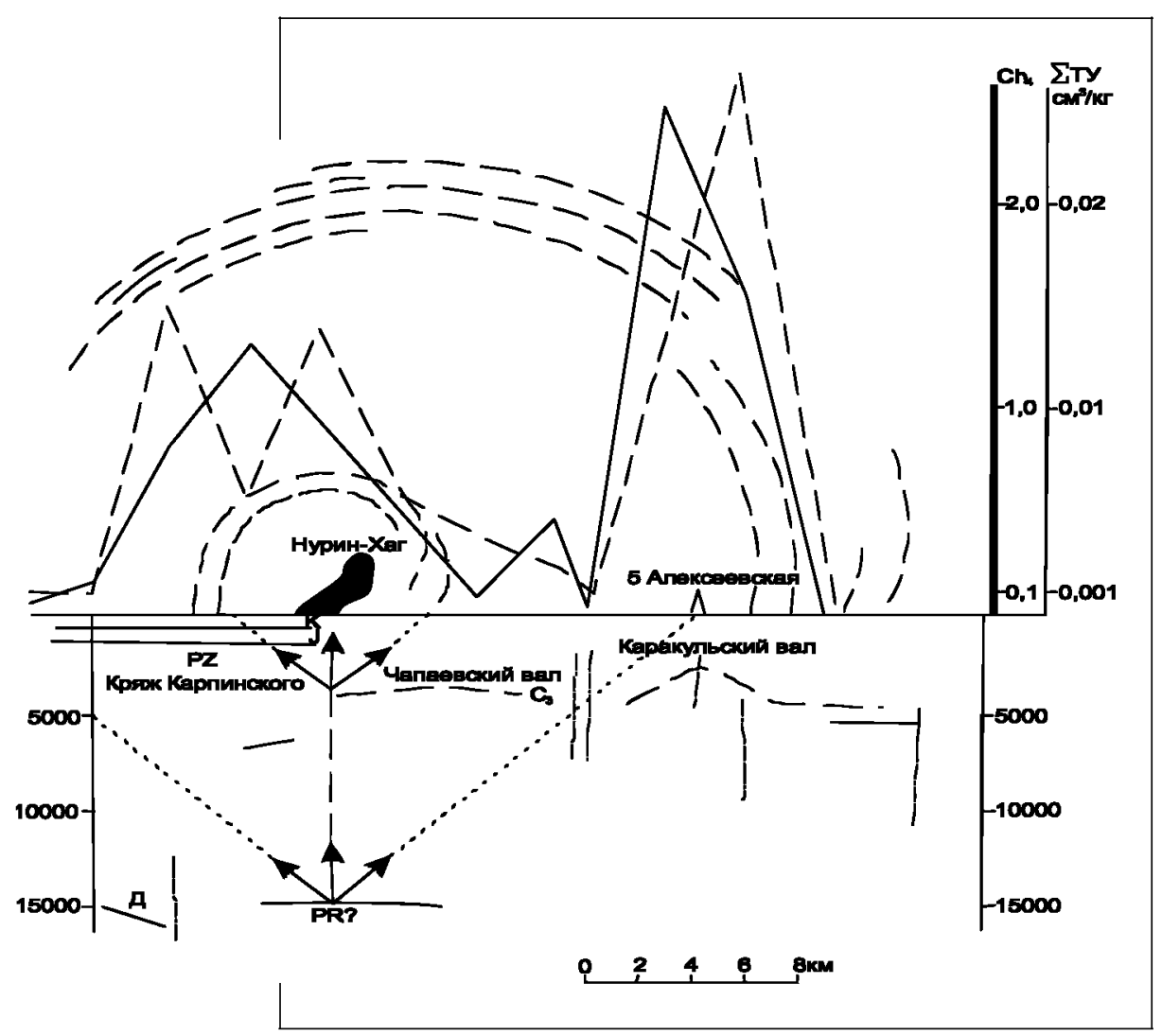

Рис. 2.

Схема приуроченности геохимических аномалий по метану и тяжелым углеводородам к космофотоаномалии и зонам тектонической трещиноватости на Нурин-Хагской площади (Автор В.М. Харченко по материалам треста "Калмнефтегазразведка"):

1 - Контуры структур центрального типа;

2-Распространение нормальных и максимальных касательных;

3 - Значение содержания углеводородов;

4 - Основные отражающие горизонты;

5 - Тектонические нарушения;

6 - Скважина с газопроявлением.

Fig. 2. Scheme of geochemical anomalies associated with methane and heavy hydrocarbons to cosmophotoanomaly and tectonic fracture zones in Nurin-Khag area. (Author VM Kharchenko according to the materials of the Kalmneftegazrazvedka trust):

1 - Outlines of structures of the central type;

2 - Distribution of normal and maximum tangents;

3 - The value of the content of hydrocarbons;

4 - Main reflecting horizons;

5 - Tectonic disturbances;

6 - Gas well. 


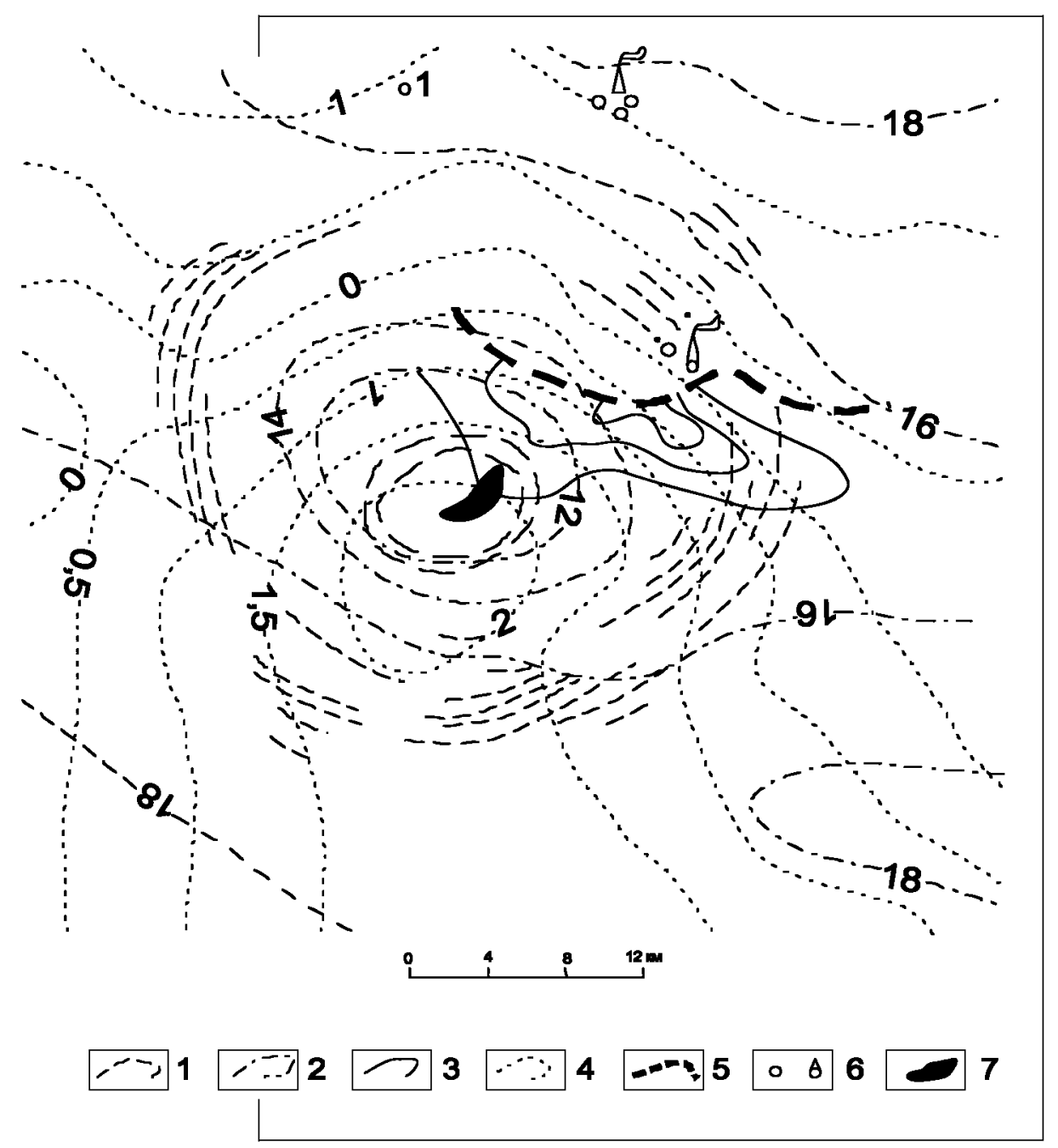

Рис. 3.

\section{Схема сопоставления космофотоаномалии с различными геолого-геофизическими данными:}

1 - структурные линии космофотоаномалии,

2 - изогипсы кровли докембрийского фундамента,

3 - изогипсы отражающего горизонта карбона $\left(1-n \mathrm{C}_{2} \mathrm{~b}\right)$,

4 - изолинии напряженности магнитного поля,

5 - разрывные нарушения (по данным геофизики),

6 - скважины: а - поисково-разведочные;

$$
\begin{aligned}
& \text { б-в которых получен газ, } \\
& 7 \text { - оз. Нурин-Хаг. }
\end{aligned}
$$

Fig. 3. Diagram of comparison of cosmophotoanomaly with various geological and geophysical data:

1 - structural lines of cosmophotoanomaly, 2 - roofing isohypsies of the Precambrian basement, 3 - isohypsies of the reflecting carbon fiber $\left(1-n C_{2} b\right), 4-$ isolines of the magnetic field strength, 5- discontinuous faults (according to geophysics), 6 - wells: a - exploration; b- in which gas is obtained, 7 - oz. Nurin-Hag 


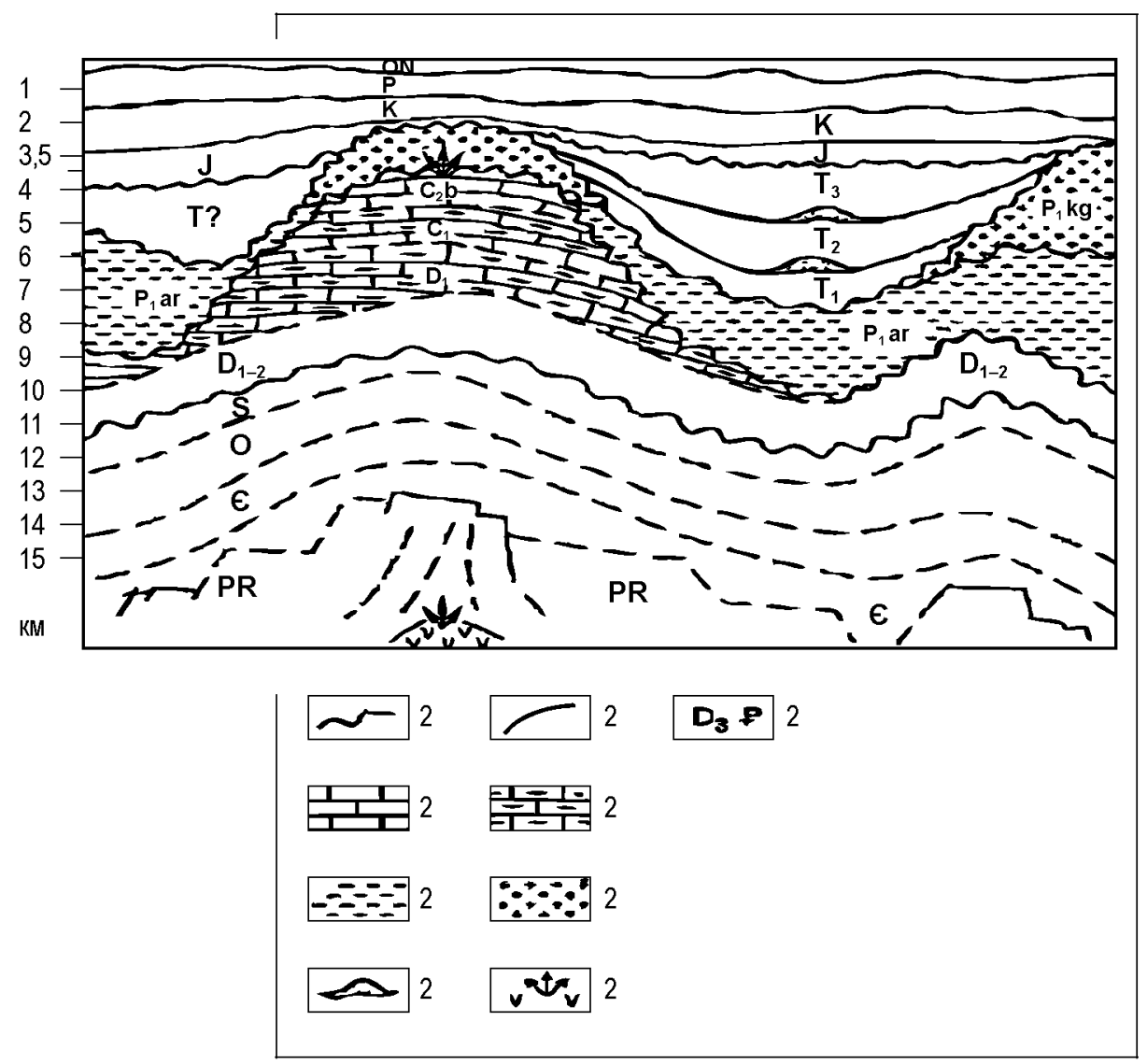

Рис. 4.

Геолого-тектоническая модель Нурин-Хагской перспективной плошали на нефти и газ с позиций эрозионно-тектонической модели и результатов интерпретации одноименной структуры центрального типа [Харченко, 1983-2004]:

1 - поверхности размыва;

2 - стратиграфические границы;

3 - геологический возраст;

4 - известняки органогенные (нефтснасы-шенные);

5 - известняки глинистые;

6 - глины;

7 - соли;

8 - газовая залежь;

9 - внедрение астенолита и распределение полей тектонических напряжений.

Fig. 4. The geological-tectonic model of the Nurin-Khag prospective was flat on oil and gas from the perspective of the erosion-tectonic model and the interpretation of the central structure of the same name [Harchenko, 1983-2004]:

1 - erosion surface; 2 - stratigraphic borders; 3 - geological age; 4 - organogenic limestones (oil-saturated); 5 - clay limestones; 6 - clay; 7 - salts; 8 - gas reservoir; 9 - the introduction of asthenolite and the distribution of tectonic stress fields. 
бинах 12-14 км, выявленного в результате сейсмических исследований АГЭ ПГО «Центргеофизика». Центральная часть ККФА практически совпадает с изогипсой минус 12 км докембрийского фундамента, а общий контур окаймляется изогипсой минус 18 км (рис. 3).

Можно сделать вывод, что в целом ККФА и ее центральная часть в первую очередь обусловлены горстообразным выступом кристаллического фундамента, который дополнительно подтверждается данными магнитометрии. Магнитная аномалия скорей всего связана с составом пород докембрийского фундамента (по аналогии с Украинским щитом), где широко развиты железистые кварциты докембрия или наличием вулканоплутонического центра [3], приуроченного к центральной части ККФА (рис. 4-5).

Естественно на поверхности Земли должна выделяться положительная гравитационная аномалия, которая естественно не фиксируется ввиду вполне вероятной залежи УВ (отрицательной гравитационной аномалии в верхней части геологического разреза). Известно, что углеводородные залежи характеризуются отрицательным гравитационным полем или отрицательной аномалией в плане. Для подтверждения результатов данных исследований проведены сейсморазведочные работы методом отраженных волн (МOB) и получена структура по поверхности отложений башкирского яруса.

Как известно, основные методы сейсморазведки - методы отраженных волн (МОВ) и преломленных волн (МПВ). Возможность регистрации отраженных и преломленных волн обусловлена тем, что упругие волны, возникающие при взрыве, распространяются в толще горных пород и образуют многочисленные вторичные волны (отраженные, преломленные, проходящие). Вторичные волны возвращаются к поверхности земли, где возбуждаемые ими колебания почвы регистрируются специальной аппаратурой. При изучении распространения отраженных и преломленных волн составляется представление о форме границ раздела, на которых они возникли, а также об упругих свойствах слоя, прилегающего к границе.

Для каждой отраженной волны, соответствующей границам раздела, может быть построен годограф. Четкие отражения получают этим методом в интервале глубин 200-10000 м, наилучшие результаты получаются для горизонтальных слоев и при углах наклона не более 15 град.

Пространственный годограф является гиперболоидом вращения с вершиной, обращенной вниз и расположенной над пунктом взрыва 0.

В случае $\mathrm{H}=0$ пространственный годограф обращается в конус. Поскольку пространственный годограф отраженной волны - гиперболоид вращения, сечение его горизонтальной поверхностью дает окружность. Следовательно, карта изохор будет представлена семейством конщентрических окружностей, расстояние между которыми постепенно уменьшается по мере удаления от эпищентра взрыва. Это очень важный момент, для объяснения наличия подобных окружностей различного размера на земной поверхности. 
Поскольку интенсивность отраженной волны редко превышает 10 $15 \%$ от энергии падающей волны, то многократное ее отражение приводит к точке полной потери энергии, т.е. мы имеем здесь факт затухающего колебания (уменьшения размеров окружностей до первых десятков метров).

Одной из новых модификации сейсморазведки является метод общей глубинной точки (МОГТ), принцип которого заключается в том, что отражающая граница изучается многократно и результат представляется в виде суммарной записи, полученной от сложения колебаний, относящихся к одной и той же точке отражаюшей границы - к общей глубинной точке [1].

Симметричное положение годографа общих глубинньх точек относительно пункта источник-приемник хорошо объясняется принципами геометрической сейсмики.

Из систем наблюдений МОГТ наибольший интерес представляют:

a) симетричная картина, когда пункт взрыва расположен посередине базы наблюдении;

б) встречная картина, когда наблюдения производят с пунктов взрыва, находящихся по разные стороны от базы наблюдений.

Самое большое распространение получили симметричные схемы, применяемые при изучении слабых отражающих границ. Предполагается, что система наблюдений МОГТ близка по своим принципам к системе излучения и распространения естественных упругих сейсмических волн и полей напряжений «активных» точек на той или иной глубине. Определение этой глубины возможно с помощью анализа топокарт и аэро-космических фотоснимков (АКФС) и на основе использовании известных положений о пространственной закономерности распространения нормальных и максимальных касательных напряжений и характера их отражения на земной поверхности в виде структурных линий или дуг-концентров различных по размеру кольцевых структур или структур центрального типа, где $\mathrm{R}=\mathrm{H}+\mathrm{h}$ (закон скалывающих напряжений).

MOB применяется при поисках и детальной разведке УВ и других полезных ископаемых, обеспечивая высокую детальность, разрешенность и точность изучения геологической среды. Применение МOB, в комплексе со структурно-метрическим методом, дает возможность выявить структурные и неструктурные ловушки полезных ископаемых, особенно нефти и газа, определить глубину и форму этих структур, получить данные о литологии, фациальном составе пород, о характере флюидов, насыщающих поровое пространство горных пород в пределах интересующей структуры. 


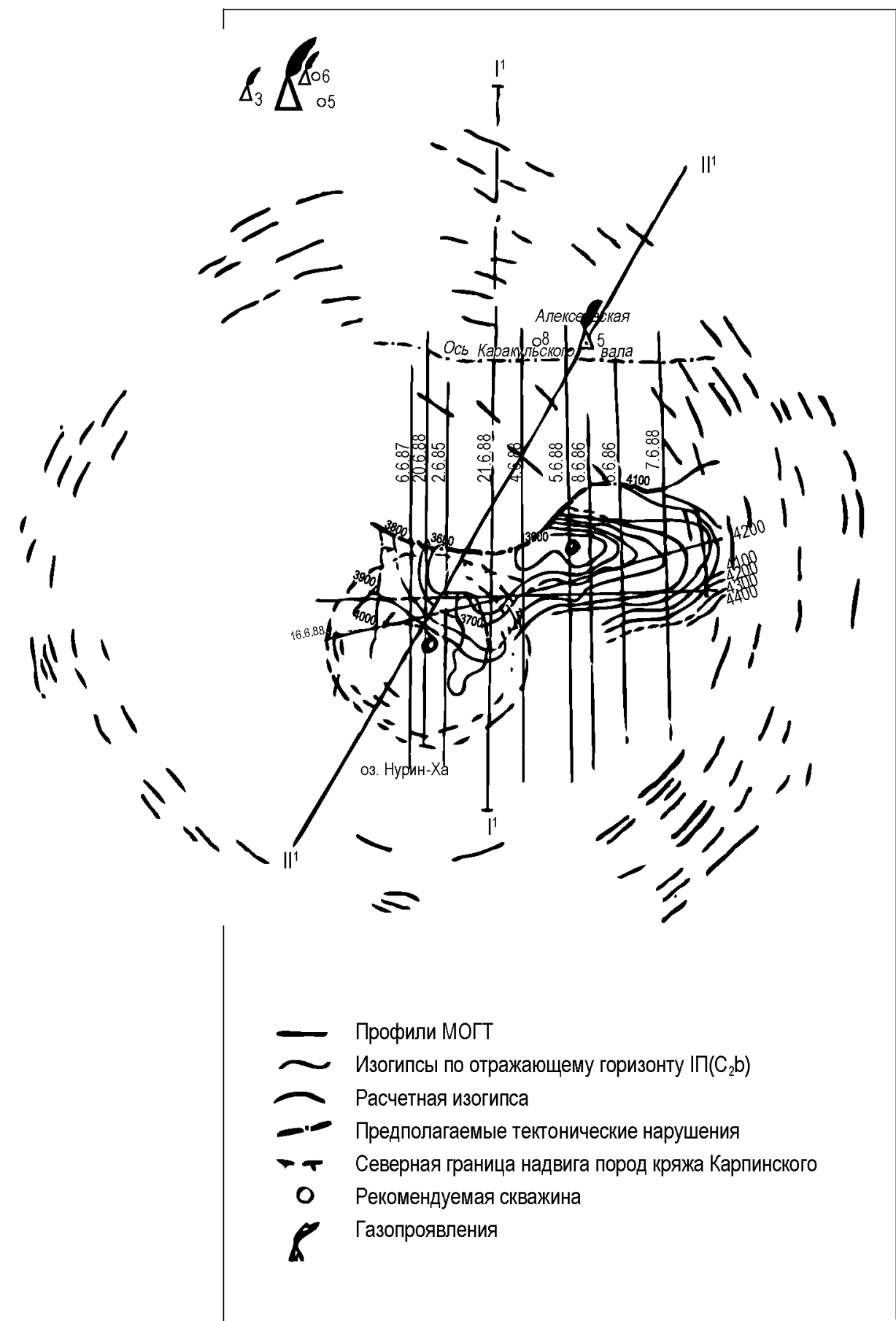

Рис. 5.

Схема приуроченности кольцевой космофотоаномалии к поднят ию по отражающему горизонту IחC $_{2} \mathbf{b}$.

Fig. 5. Scheme of confinement of the annular cosmophotoanomaly to the rise along the reflecting horizon $I \Pi \mathrm{C}_{2} \mathrm{~b}$. 


\section{Результаты исследований и их обсуждение}

Оперативный, основательно аргументированный и экономически целесообразный прогноз скоплений УВ в настоящее время немыслим без применения комплекса дистанционных, магнитных и гравитационных методов. Эти методы становятся не только неотъемлемым, но и первым звеном технологической схемы поисковых работ на нефть и газ в различных регионах страны и мира.

Геофизические методы в комплексе с дистанционным структурно-метрическим методом являются косвенными, дальнодействующими, обеспечивающими равномерность, объемный характер получаемой информации и практически неограниченную глубину.

При этом производительность аэрокосмических съемок и геофизических работ значительно выше, а стоимость в несколько раз меньше по сравнению с разведкой с помощью неглубоких (до 100 м) и в сотни раз меньше при бурении глубоких (свыше 1 км) скважин. Повышая геологическую и экономическую эффективность изучения недр, комплексные дистанционные и геофизические методы исследования являются важнейшим направлением современной геологии.

В результате анализа карт гравитационного и магнитного полей территории Центрального Предкавказья, и наложении на них структур центрального типа радиусом 30-35 км, отмечается частичное (50\%) совпадение наложенных аномалий с геодинамическими центрами, что связывается с рудными телами (титаномагнетита, циркона, золота и др.) Остальные геодинамические центры приурочены к минимальным значениям гравитационного поля, вероятнее всего связаны с углеводородными залежами. Особо такая картина представляется на территории Ставропольской СЦТ, где к уже известным месторождениям газа (Сенгилеевское) приурочивается кольцевая магнитная аномалия, и практически отсутствует гравитационная.

Подобная картина нами представляется выше и для Нурин-Хагской структуры в Калмыкии, что может быть доказательством наличия здесь УВ залежи.

Особо следует отметить четкую приуроченность известного Бешпагирского месторождения редких металлов (титаномагнетита, циркона и др.) с наложенными данными, что позволяет связать это и с другими наложенными аномалиями гравитационных, магнитных полей и геодинамических центров территории Центрального Предкавказья (рис. 6). 

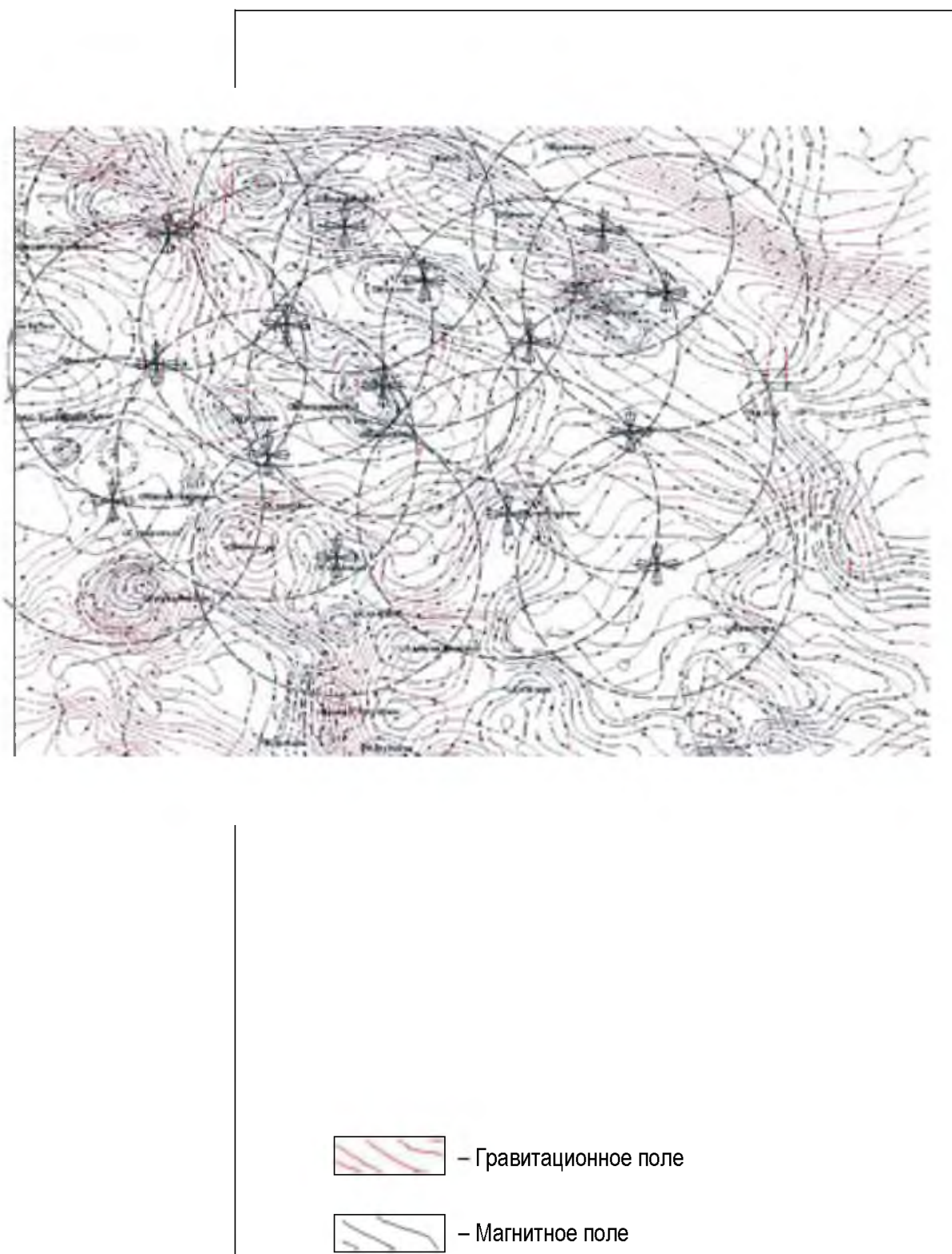

nc. 6.

\section{Наложение карт изолиний гравитационного, магнитного полей и структур центрального типа территории Центрального Предкавказья.}

Fig. 6. Overlaying maps of isolines of gravitational, magnetic fields and structures of a central type on the territory of the Central Ciscaucasia. 


\section{Выводы}

1. Приводится геофизический критерий поисков одновременно залежей углеводородов и рудных залежей, что предоставляет не только новизну, но и очевидную практическую значимость. .

2. Проведены работы по выявлению перспективности рудонефтегазоносности рассматриваемых территорий, в том числе и на Нурин-Хагской площади в Калмыкии.

3. Работа носит научно-методический уровень исследований, благодаря которой возможно оценить перспективы рудонефтегазоносности любой территории, где есть материалы космической съемки, наложенных магнитных и гравитационный полей.

4. В результате обработки карт изолиний гравитационного и магнитного полей территории Центрального Предкавказья и сопоставления с наложенными аномалиями гравитационного и магнитного полей, на основе разработанной методики, определены перспективные участки рудонефтегазоносности территории Центрального Предкавказья.

\section{Библиографический список}

1. Бондарев В. И. ОСНОВЫ СЕЙСМОРАЗВЕДКИ. Учебное пособие для вузов. Екатеринбург: Издательство УГГТА52003. 332 с.

2. Зеливянская О.Е. Создание цифровой модели гравитационного и магнитного полей территории Предкавказья // Материалы VII ежегодной научно-практической конференции Северо-Кавказского федерального университета «Университетская наука - региону» - Ставрополь, 2019.

3. Павленкова, Н.И. Ротационные движения крупных элементов Земли и глобальная геодинамика [Текст] / Н.И. Павленкова // Ротационные процессы в геологии и физике. М.: КомКнига, 2007. C. 103-115.

4. Харченко В.М. Геолого-тектоническая модель Нурин-Хагской космофотоаномалии на территории Калмыкии // Тезисы доклада 27 Международного Геологического Конгресса. Москва, 1984. T. 8. C. 528

5. Харченко В.М. Природа структур центрального типа и закономерности распространения залежей углеводородов, локальных и региональных очагов землетрясений. Ставрополь: Вестник СевКавГТУ, №2(6). 2006. С. 48-53. 


\section{References}

1. Bondarev V.I. BASIS OF SEISMIC EXPLORATION. Textbook for universities. Ekaterinburg: Publishing house UGGTA52003. $332 \mathrm{c}$. (In Russ.)

2. Zelivyanskaya O.E. Creation of a digital model of gravitational and magnetic fields in the territory of the Ciscaucasia // Materials of the VII annual scientific-practical conference of the North Caucasus Federal University "University Science for the Region". Stavropol, 2019. (In Russ.)

3. Pavlenkova, N.I. Rotational movements of large elements of the Earth and global geodynamics [Text] / N.I. Pavlenkova // Rotational processes in geology and physics. M.: KomKniga, 2007. S.103115. (In Russ.)

4. Kharchenko V.M. Geological - tectonic model of the Nurin - Khag cosmophoto anomaly in Kalmykia // Abstracts of the 27th International Geological Congress. Moscow, 1984. T. 8. S. 528. (In Russ.)

5. Kharchenko V.M. The nature of the central type structures and the patterns of distribution of hydrocarbon deposits, local and regional centers of earthquakes. Stavropol: Bulletin of SevKavGTU, No. 2 (6). 2006. S. 48-53. (In Russ.)

\section{Поступило в редакцию 10.11.2019, принята к публлкации 02.12.2019}

\section{O6 авторах}

Харченко Владимир Михайлович, Доктор геолого-минералогических наук, профессор кафредры геологии нефти и газа Северо-Кавказского федерального университета (СКФУ).

355000 , г. Ставрополь, пр. Кулакова 16/1 (корпус 16).

Телесрон: +7(906)-468-22-64.

E-mail: kafgog@ncfu.ru.

Лапта Денис Васильевич, аспирант кафедры геологии нефти и газа Северо-Кавказского федерального университета (СКФУ), 355000 , г. Ставрополь, пр. Кулакова 16/1 (корпус 16).

Телефон +7(906)-491-34-26

E-mail: d.lapta@yandex.ru.

Неркарарян Алина Евгеньевна, специалист по учебно-методической работе кафедры геологии нефти и газа Северо-Кавказского фредерального университета (СКФУ), 355000, г. Ставрополь, пр. Кулакова 16/1 (корпус 16).

Телефон +7(905)-445-21-79.

E-mail: alina-domareva@rambler.ru. 


\section{About the authors}

Kharchenko Vladimir Mikhailovich, Doctor of Geological and Mineralogical Sciences, Professor at the Department of Geology of Oil and Gas, North-Caucasian Federal University (NCFU), 355000 , Stavropol, 16/1 Kulakov Ave. (building 16). Phone: $+7(906)-468-22-64$.

E-mail: kafgog@ncfu.ru.

Lapta Denis Vasilievich, a graduate student of the Department of Oil and Gas Geology of the North Caucasus Federal University (NCFU), 355000 , Stavropol, Klakova Ave. 16/1 (building 16). Phone: +7(906)-491-34-26.

E-mail: d.lapta@yandex.ru.

Nerkararyan Alina Evgenievna, specialist in educational and methodical work of the Department of Oil and Gas Geology of the North Caucasus Federal University (NKFU).

35/1000, Stavropol, 16/1 Kulakova Ave. (Building 16).

Phone: +7 (905) -445-21-79.

E-mail: alina-domareva@rambler.ru. 